\title{
SOME REMARKS CONCERNING THE REFERENCE OF MENTAL AND LANGUAGE REPRESENTATIONS*
}

\begin{abstract}
This paper is an attempt to answer the question, what is exactly represented by our thoughts or language expressions. At the beginning, the article presents the main philosophical problems regarding the understanding of the nature of the object of reference of such representations as names or descriptions. Is the name directly referred to the real object or rather to the content of thought? What about cases when the name cannot be referred to the real object? What is the relation between the intentional subject connected with every name (or description) and the external object to which only some names can be referred to, and which one is prior to the constitution of representation? The idea to understand the subject of mental or language representations as a complex structure which has a relational nature is the solution proposed in this paper. This structure is constituted by cognition and ties internal elements of a given representation such as the content with the elements which are external with regard to this given representation. This structure reflects such elements as the content of representation, the way in which this content is given, the correlate of the content and its mode of existence as well as additional systemic information coordinated with given representation. Some consequences of this proposal are discussed at the end of the article. It is explained how the differentiation of the elements of this structure can lead to different types of reference. The basis to understand the issue in question is the relation between internal and external object of reference. It can be interpreted (as is suggested in the paper) as a connection between internal elements of the described structure.
\end{abstract}

Keywords: representation; Peirce; language

1. Introduction. 2. The dualism of the object of representation. 3. Object and content of the representation. 4. Structure of the object of representation. 5. Conclusions.

* This article was originally published in Polish as: J. Buczkowska, Kilka uwag o przedmiocie reprezentacji, Studia Philosophiae Christianae 45(2009)2, 69-90. The translation of the article into English was financed by the Ministry of Science and Higher Education of the Republic of Poland as part of the activities promoting science - Decision No. 676/P-DUN/2019 of 2 April 2019. Translation made by GROY Translations. 


\section{INTRODUCTION}

The question about the object of thoughts and language expressions raises many well-known difficulties. The distinction between an external, real, thought-independent object and intentional, internal object of mental acts and linguistic expressions leaves an open issue of their mutual relation. All the problems related to this issue are well known, so I will not quote them, although the following analyses will be conducted in their context.

Acts of perception, conceptual thinking, verbal communication, etc., that is, mental acts and acts of linguistic communication, are today interpreted by many philosophers as processes of representation. The concept of representation is nowadays used quite commonly to describe and explain the nature and cognitive functions of both consciousness and language ${ }^{1}$, although each author has a slightly different understanding of representation itself. If elements of consciousness, such as sensory impressions, imagining, concepts or signs of language are representations according to this approach, then the question of what do they represent is legitimate. The analysis of the function of representation will reveal the nature and role of the object of representation and the ways it is presented.

The analysis of the general, internal structure of the relation of representation, understood as a sign relation, was presented in detail by C. S. Peirce ${ }^{2}$, who made the concept of representation the key to understanding thought and language. The relation of representation includes, in addition to the means of representation, what is represented and an element of interpretation. Peirce stresses that the very function of representation implies its relational nature, consisting in the relationship between what is represented, what is used for performing representation and what it evokes in the consciousness as its interpretation.

1 For example: F. Dretske, J. Fodor.

2 Cf. C. S. Peirce, Wybór pism semiotycznych, transl. R. Mirek, A. J. Nowak, Warszawa 1977. 
Nowadays, the name "representation" is often used in a narrower sense onlywith regard to the veryelement bywhich the whole process of representation is carried out and which Peirce called a representamen and which, in his opinion, is only one of the elements of a richer relationship.In contemporary representationalism, there is even more a need to define what different types of mental or linguistic representations represent. The basis on which the representation is made and what is the object of it. The following is a proposal to ask a question about the object of representation, primarily the object of linguistic expressions, but also of other cognitive acts, in the context of their function of representation.

Including under the general name of the object of representation what is perceived and to what mental concepts and linguistic expressions relate, it should be taken into account that the object which representation directly presents is constituted in relation to what is represented and the way of presenting it in a specific representation. There is a need to distinguish between the external object and the internal (intentional) object of representation. So let us assume that the object of representation has a complex structure and we will search for its elements in this article. This structure should at least partly explain some of the difficulties concerning the nature of the object of mental and linguistic representations, such as the the difference between an intentional object and the real thing, or the possibility of representing non-existent objects. This structure will be used to characterize the object of representation for various types of representation and to define the relation between the intentional object of representation and the external object which is represented.

Most of the considerations will be carried out using the example of linguistic representation, but both the analyses themselves and their results will be generic and will also apply to other types of representation. Type of representation different than the linguistic one will be clearly indicated.

The name "object of representation" will be used most generally to describe what is represented in a given act of representation and remains outside it, it may be an object, a concept, an impression, 
a fictional object, etc., it is external to the act of representation. "Real object" is an object external to consciousness. "Internal object", on the other hand, is an object which is given in representation and limited only to the represented aspect. These distinctions may be useful for further consideration. If there is no clear indication in the text of what is referred to as "external" or "internal" for example, it should be understood in the sense given above.

\section{THE DUAL ASPECT OF THE OBJECT OF REPRESENTATION}

When looking for an answer to the question of what language expressions such as names represent, one always encounters an irremovable duality of what can be regarded as the object being represented. If it was assumed, for example, that the expression "Morning

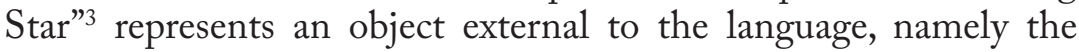
planet Venus, it was at the same time indicated that it only captures some aspect of this object, namely that it is visible in the morning sky. The expression does not reveal the real object in all its content, but only a certain aspect of it, presented cognitively and linguistically. This reveals the fundamental property of representation, which is that the object being represented is not fully present in it, but is given only in some way. It is this aspect that constitutes the internal object of representation in terms of content, and only the internal object is directly given in representation.

Peirce distinguishes between a dynamic object, i.e. an external object that exists independently of representation, and an immediate object, i.e. an aspect of a dynamic object, for the purposes of a given representation. According to Peirce, ,it necessary to distinguish between the immediate object - the object as it is represented by the sign - from the real object (but not since this object may be completely fictitious, I must therefore find another term), let's say, rather, from the dynamic object, whose sign is by its very nature un-

3 I am referring to G. Frege's theory of sense and denotation. Cf. G. Frege, Sens i Znaczenie, in: Idem, Pisma semantyczne, transl. B. Wolniewicz, Warszawa 1977. 
able to express, leaving the interpreter the task of further cognition in a complementary experience"4.

The idea that only fragmentary content, a certain isolated aspect of the external ${ }^{5}$ object of representation is given in a representation, is also included in the concept of intentional object as opposed to the external object, as well as manifests itself in the distinction between denotation and meaning, introduced by G. Frege. Many language names, such as "Odysseus", do not have, according to Frege, an external object, but only a sense that exists for each type of linguistic representation ${ }^{6}$. The object, i.e. the meaning of a language sign, according to Frege, exists only in some cases. In Peirce's view, on the other hand, a dynamic object of representation always exists, as does an immediate object, although not necessarily in the way real objects exist. A real object is one type of dynamic object, while an immediate object is always an intentional, internal object.

The function of representing something consists in, according to Peirce ${ }^{7}$, the the occurrence or use of something (a sign that is called a representamen) instead of something else (an external object) in a certain aspect (an internal object), that is the replacement of something by something, but only in some aspect in a situation where what is represented does not occur. A representing element or representation in the narrow sense (representamen in Peirce's terminology) does not present itself as an autonomous object, but only as a specific, aspectual substitute for what it represents. However, it does not fully replace what it represents, but only occurs instead, and this "instead" is clearly stated and known in the case of representation. The representamen, according to Peirce, is a sign of what its represents.

\footnotetext{
4 C. S. Peirce, Wybór pism semiotycznych, op. cit., 116

5 External to a single act of mental or linguistic representation and not to language or thought in general. Thus, an external object of a given representation may be the content of consciousness as represented, e.g. a concept, a word or its meaning as what is represented. The internal one will be what exactly the representation from a given concept or general meaning of a word represents.

6 cf. G. Frege, Sens i Znaczenie, op. cit., 61.

7 Cf. Peirce, Wybór pism semiotycznych, op. cit., 131.
} 
Mental or linguistic representations can have both real things and mental constructions as their object. A thought or language may represent, besides real things, also other thoughts, abstract or fictional content, impressions, words, etc. A thought may juxtapose a representation of a real and an imagined situation side by side and retain the distinction between their respective status. We can all imagine, for example, a situation more convenient than the one we are in, and we are aware of the reality of one and the fictionality of the other. This knowledge is external to the representation itself, it is not derived from its content. However, this knowledge cannot be omitted as it affects the constitution of the object of representation

Let us stop at the case of representing external things by language expressions. We will say that what this expression represents is precisely it. For example, the expression "Morning Star" represents the relevant astronomical object - the planet Venus. It is an object external to thought and language. However, the planet Venus is not given in all its content in the representation. The expression directly represents a conceived object, cognitively captured exactly by the content it represents. The name "Morning Star" has the planet Venus as its external object, while the internal object only covers the aspect of the planet Venus that reveals the content of the name, that is, its visibility in the morning sky. What is the relation of these objects to each other? Neither epistemologically (constituted by other cognitive content) nor ontologically (one is a real object and the other a mental one) are they the same, although on the other hand, it is difficult to deny them a certain identity. The content of the internal object is part of the content assigned to the external object, and the content of the internal object, although intended or given linguistically, refers after all to the object in the sky and not in the mind. However, only the aspect of the external object revealed in the representation is the one that reveals the internal object.

Therefore, is this internal object an appropriate object of representation? The answer to this question is not obvious. The basic function of language is the the possibility of using it for speaking about the extra-linguistic world, real things and our thoughts. 
When we apply language expressions to a real object, we are clearly dealing with two closely related concepts of the object of representation. With the concept of an external object or, according to Peirce, a dynamic one, and the concept of an immediate object, an internal object of representation. Internal and external objects fulfil different cognitive roles. The act of representation capturs something else, something that is given, but is not included in it. It may be constituted in another act of representation, or it may exist outside the realm of thought, but it cannot be an internal element of a given act of representation.

It can therefore be concluded that the object of representation, that is, what is represented, is constituted both by what Peirce describes as a dynamic object and an immediate object. Both these aspects are equally important and irreducible in a full description of what is represented. This duality is non-removable because it is related to the function of representation and indicates the relational nature of the object of linguistic representation (and any other). It should therefore be reflected in the structure of the object of representation.

\section{OBJECT AND CONTENT OF REPRESENTATION}

Distinguishing between the object and content of mental representations and of linguistic expressions often leads to to understanding them as if they were almost independent elements. But ignoring their close relationship gives an incomplete picture of the representation process. For different types of representations, the distinctiveness of the internal and external object seems more or less clear. For example, if it is the name (descriptive) of a real existing object, e.g., the "current Prime Minister of the Polish Government", then it is easy to grasp the difference between the content of a representation, i.e. that aspect of the object that is given in the representation, which is the internal object of the representation, and that which is its external object. This is easily noticeable when, based on other cognitive acts, we know additional aspects of the represented object. 
In many cognitive or communicative acts, however, we know the object content only from a given representation and we only know the internal, intentional object of the representation. This is the case, for example, in sensual cognition, where the only available way to capture an object is to represent it by means of impressions. External things that we get to know, e.g. by means of sight, are given to us only as visual images, i.e. aspects of things represented in the process of seeing. Only these visual contents are the immediate, internal object of visual representation, which is carried out by appropriate neural structures. However, despite the direct accessibility only to the content of the internal object, we consider our visual impressions to be a representation of the external object, which can also be captured by other senses. We say then that this representation has a real external object that determines the internal object.

In the process of sensory cognition, a spontaneous distinction is made between the internal object, i.e. the inner content of the impression itself, and the external thing, and the reference of one to another. The internal object is intentional and never replaces the whole thing, only some aspect of it. What is seen can also often be heard and touched. This creates a richer representation of the external object, but it is still incomplete and cognitively open to further content enrichment.

In the case of sensory cognition, we usually deal with some kind of projection of real external things into the space of possible sensory experience. Experiencing something that is only a construct of consciousness is not a basic type of sensory experience, although such accidents also occur, e.g. when we are hallucinating. Thus, despite the distinction between the external thing and the internal object of sensory represenatation there is also a certain unity between them ${ }^{8}$. Although the thing is given in sensory cognition only as the content of perception, it is this thing and not the content of perception itself that is known. External object is considered a cause and a determinant of qualitative content.

8 The dispute over the relation between real and intentional objects is described by, among others: M. Maciejczak, Świadomość i sens, Warszawa 2007, 154-162. 
A dynamic object, an external object is present in sensual cognition next to the intentional, internal object and remains inextricably linked to it. This close link between these two aspects of the object of representation has been stressed many times in philosophy, for example in Thomistic philosophy or phenomenology. Related problems appear also in contemporary representationalism ${ }^{9}$. This duality of the real thing and its cognitive content, more generally, content that is represented, should be reflected in the structure of the object of representation.

Such an approach indicates, on the one hand, that the object of representation, if a real thing is represented, is the relationship established by that thing and its cognitive content. This makes it easy to explain the fact that the same thing can be represented in different aspects. The thing that serves as the basis for the content represented plays the role of uniting all the aspects into one concept of an object, which makes that all the content is predicated on one object. The difference in the content related to the various aspects of the subject differentiates its various representations, however, there remains a common link in the form of one basis of these representations which is the real thing.

Pierce assumes that an object in a cognitive relationship cannot be given fully as something homogeneous, but is a two-argument relationship in which, as a single component, there is an independent thing, a certain monolith, a "thing in itself", the "First" as the author describes it, and as a second component of the relationship there is a cognitively dependent aspect of that thing ${ }^{10}$. The object is the second. It is what it is because of something else, in opposition to what it occurs. The basis of this relationship is the causal relationship between the thing and its cognitive perception. Such a relational approach to the object of representation (cognition, language, thought) seems very promising to explain the aforementioned of dual aspect of represensted object. However, it seems that this relationship should be enriched with additional elements.

9 Cf. F. Dretske, Naturalizowanie umysłu, transl. B. Świątczak, Warszawa 2004, 39-43.

10 Cf. C. S. Peirce, Wybór pism semiotycznych, op. cit., 119, 222-228, 259. 
There is a clear difference between the mental representation of reality in the form of sensory cognition and the conceptual or linguistic representation of that reality. If we consider linguistic representation, it can be seen that, unlike sensory perception, what is represented is not in some basic way a reflection of reality. We can think or describe imagined situations or objects, even non-existent ones. What does the name "Pegasus" represent? It represents an imaginary object. In cognition, there are mechanisms for distinguishing between what is given externally and what is constructed by the mind. Experiencing or imagining some kind of object content, we are aware of which process of representation occurs.

If we consider human linguistic activity, it turns out that the function of language concerning the construction of such imaginary situations or objects is as important as the function of reflecting reality. Thought also has similar properties. Representing and reflecting reality are two different functions. These functions are in many cases combine, since representation can be a certain reflection of reality (things, their properties and arrangements). However, the space of representation is also used to obtain images of non-existent situations, possible worlds, to perform any operations on the elements represented or reflected and to create new representations. Language can represent imaginary objects, which the senses do not often do. We can think of the blue sun, although we will not get a sensual image of this object. Words and sentences can represent our ideas, not just real things.

On the other hand, language is also used to talk about things. In linguistic cognition, or many acts of communication, language words refer to external things. This makes the relationship between the internal and external object more diverse in linguistic representation than in sensory cognition. An internal object of thought or language does not have to be a real object given i some aspects but it cuould be given as the content correlate that has no equivalent in real world.

This property of representation plays an important cognitive role. We can perform certain operations on elements of representation. The function of cognition is a certain representation of the world. 
But cognition is subordinated to purposeful action in the world. The possibility of creating imagined "possible worlds", and the choice of the most appropriate of imagined situations as a goal of activity is strongly connected with the cognition of reality and adapting it to expectations. Understanding the cognitive function only as a reflecting function is too narrow. Cognition, especially scientific, often operates with representations of abstract, theoretical, etc. objects. What are these objects? Do they come down to the content of the representation?

Although pragmatism in the philosophy of language has initiated and developed the view that language also has other important functions besides the function of reality representation, its creative role as a creator of representation of imaginary situations is still underestimated. Over the last century, the function of the reflection of thoughts and language, their relationship with reality have been emphasised, omitting the second aspect, the creative aspect. It seems that a more complete, though perhaps still not exhaustive, description of the object of representation may be given only if both aspects are taken into account.

When presenting an object as a two-element relation, as suggested by Peirce, and assuming that its components are the object - as something represented - and its content characteristics, it should be taken into account that among the linguistically represented objects some have only a content representation, as well as those that have very poor content, such as the expression "this", "what I'm talking about", etc., which is a reference to something beyond the expression itself.

Frege indicated these two components as two aspects of the use of the name. The name fulfills its representational function based on their mutual relationship. On the one hand, a name such as "Morning Star" refers to the planet Venus, on the other hand, it cognitively captures only a certain aspect of the planet and links a certain content to it. For Frege, the sense, that is, the internal content of a representation, is what is necessarily associated with the expression. Frege that links the cognitive function of expression with the sense in a significant 
way ${ }^{11}$. However, having a denotation, that is, an external object, distinguishes some names, giving them a function of reflecting reality. Only sentences in which all names have reference can be true or false because only such expressions can be referred to the real world. The lack of denotation, that is, an external reference object which, according to Frege, may belong to a domain of things, physical events, or a domain of logical and mathematical objects, deprives the expression of the function of mapping the reality, but does not deprive it of the function of representation as such.

The sense of an expression is directly and necessarily connected with the expression and presents its purely intentional content. The knowledge of denotation requires additional knowledge of the world, which is not contained in the sense of expression. This knowledge requires additional representation. For example, besides the linguistic knowledge of the meaning of the expression "Morning Star", we also have a sensory experience of an astronomical object, e.g. we can see in the sky this bright and appropriately located object, which we call the Morning Star, we associate the appropriate content with this name as its sense. Thus, a certain inseparable relationship arises between reference and content, denotation and sense, the external and the internal object of representation. The two elements of this relationship are complementary to each other. Only their combination gives full understanding of the name. Neither the sense nor the denotation itself constitutes complete linguistic knowledge of the name. However, it is not possible to a certain inseparable relationship arises between reference and content, denotation and sense, the external and the internal object of representation. these elements in isolation. They are always correlated. The object of cognition, as the classical philosophy put it, has always had the aspect of content and the aspect of existence recognised in different kinds of judgements ${ }^{12}$.

What we learn or represent is always seen as something with certain qualities. What we know or represent is always given as some-

11 Cf. G. Frege, Sens i Znaczenie, op. cit., 61.

12 Cf. M. A. Krąpiec, Język i świat realny, Lublin 1985, 91. 
thing having certain features. Something in sense of entity given only as a centre combining the assigned features in unity into the concept of a given object and a set of featuers anchored in this focus. Without the properties given as sense, (a pure object in opposition to the content) is unrecognized, unrepresented. It becomes a component of a relationship if we attribute at least one feature to it, such as being what you say or think about. This something, as a basis for the content, is present as a real or assumed holder of the properties assigned to it. Russell views the object in this sense, as an argument fulfilling a function defined by the sense of a description or a sentence ${ }^{13}$. The sense fulfills the function of a predicate which is assigned to the object. However, it is the object that determines the features included in the description, and not the description that determines the object.

Apart from the qualitative characteristics, we also have an element that determines the way the the argument of description i. e. the correlate of contetnt exists. The sentence "The current king of France is bald" makes the argument that he is currently the king of France, that he is bald and that he exists in reality. However, none of the existing real arguments meets such a description, so the name of the current king of France is empty and the sentence is false. Knowing the name, besides knowing its sense, is linked to an object of reference i.e. the correlate of content. This reference is always associated with some description of the object of reference, even such as: "is a completely unspecified thing to which the name refers", or at least an indication of a given thing providing its sensory characteristics, which replaces a linguistic expression of indication.

Based on the above, we can assume that when the represented is a real-existing thing, object of represenation is a certain relationship with a certain structure. Within this structure, it is possible to distinguish, on the one hand, a certain content, given as a sense of expression and on the other hand, the referent of this content, which is its cause and determinant.

13 Cf. B. Russell, Denotowanie, transl. J. Pelc, in: Logika i język: studia z semiotyki logicznej, ed. J. Pelc, Warszawa 1967. 
What do general names, such as "a man" or "an animal”, represent? As language expressions, they have the content assigned to them in that language. This content is not related to just one, specific, individual thing, but can be assigned to many things. However, it is not these individual things that are the source of unity of content. This source is a correlate of content having the character of a general, intentional object, which has the character of a variable that can be truly replaced by the elements of a specific set. Content of predicative notions of "animal" can be fulfilled by many arguments.

The general name can function as a description, i.e. as the content given in a general concept, e.g. the name "a human". What is the object of this name? The name a "human" does not represent all people, although it can be used to refer them, that is to say, one can truly attribute the content that is contained in the concept of human to every human being. This name represents a schematic, albeit dynamic, general object. General names represent a general object, abstract, thought or language construct.

One may ask if it is justified to introduce general subjects as correlates of the content of concepts that exist only as components of thought, next to concepts. If we understand the concept as here, as a mental content, then this content is the content of some object. Frege proposed to understand the concept as a complex unity of content, as a function, as a predicate, which can only be satisfied by objects, represented by unit names. This is what happens when we say, for example, that NN is a good person. But when we say that a human has changed his silhouette over the centuries, we do not mean all people, nor do we mean a particular human, because no individual has changed his silhouette over the centuries, nor the concept of the human, because it is not the concept of man that has changed his silhouette over the centuries, but people. We mean that there is a difference between any human being belonging to different ages of species development. Here we have an internal object of representation, defined by a certain content and its correlate, which exists as abstract in a way of a generalised scheme based on the characteristics of individual things. So if we want to answer the 
question of what a general name refers to, e.g. the name of a human being, we have to consider whether we mean a specific utterance, an act of linguistic representation, or a name belonging to a universal language (dictionary). A specific utterance, a specific linguistic representation may refer to an individual real object falling under the concept of human being or to a general abstract object, conceived, corresponding to the content of the concept of human being. The dictionary name represents only a general object with the content of the term human being.

The question about the object of representation remains the most pressing when it comes to names that are not matched by any existing object, such as "Golden Mountain" or "Pegasus". Kazimierz Twardowski distinguished the content and object of a name even in the case of names that do not correspond to anything, such as the name "diagonal square". The content of a name always exists, but the object is declared non-existent. It appears as a correlate of content, as a link between the features atributetd to the name, but it not exist in any other way than an internal relation to the content. What object, then, are we talking about that does not exist: is it internal object, intentional, conceived or external one to the representation? What role does the content correlate, often simply called an object, play in the representation that it has to be distinguished from the content? It is a kind of a focal point around which the features attributed to it are concentrated, creating a single concept, a concept of this very object. It is not only a link between the content, but it is its foundation and the source of its unity as attributed to the same thing. Only in such an approach, as a characteristic of something that is both diagonal and square, is the content of the expression "diagonal square" contradictory. A real thing can be diagonal or rectangular. But an object cannot be both at the same time.

The content correlate is also what is given in the various acts of representation in different ways and what forms the basis for the unity of all these cases. Correlate of content is the cause that, when we say Alexander the Great's teacher and Plato's greatest student, we are talking about the same man. The content itself does not constitute 
an object, but only partially characterises it. The object remains open to the content, its enrichment and changes. It is about the object, and not about the content, that we declare existence or identity with another. (Frege "Morning Star" and "Evening Star" have a different content, but have the same content correlate, i.e. a narrowly understood object). It is similar for non-existent objects. For example, we can decide on the identity of Oedipus' mother and Oedipus' lover, although the content of the expressions and the internal object of expressions are different in both cases. Identity refers to the content correlate. The correlate is what unites different contents into a concept. The object of the name, e.g. the mythical Zeus, is what unites various information about it, also that it is a product of imagination. The content of the name "Zeus" also includes the fact that it is a mythical character, but the correlate of content has a different function. The name refers to correlate of content and not to the content. An object as a content correlate is represented by different approaches to the content assigned to it. It is not the name (as a representamen) that unites the content itself, but the referent of name, in this case the correlate of content. In this sense, one can even talk about something that is only conceived and that elements of content are even contradictory, such as a "diagonal square".

A correlate is a condition that the content is is assigned to something. "Red" as a feature of observation can only be the content of something perceived, not an object. Something that is red is just a red object. The content and the correlate belong to the constitutive elements of the object. Something completely devoid of content is not an object, as it is not known in any way. Similarly, the characteristics themselves as the content of a representation, without reference to a common basis, to a single focal point, are not an object. The content correlate is, therefore, what constitutes the content as a content of someting. It only plays a focal, source or causal role in relation to the content, although it does not identify with it.

Correlate and content play a different role even when talking about unrealistic things or situations. Content is a way of representing what is represented. The object as a correlate of content is 
a condition of representation itself. What is represented exists in some specific way or is a logical contradiction. But it always transcends beyond the content, only beyond the content do we find its existence or not find its existence. There is a known difficulty that arises in the case of a content correlate that has no equivalent in any logically possible or real object.

\section{STRUCTURE OF THE OBJECT OF REPRESENTATION}

What characterises the object of representation alongside the content and its correlate is the way of existence of content correlate. This way of existence is always given additionally, although not by the content of representation itself. We have additional knowledge about the fictionality of literary objects, or about the reality of sensually experienced real things, about the contradiction of content and the non-existence of diagonal squares. This knowledge concerns the ontic status of what the representation refers to, whether it is a concept or a mental image or an external thing. Without this additional but important knowledge, it is impossible to determine what specific representations refer to. Thus, next to the object or content correlate, one should distinguish the way of its existence. We can think about our thoughts or we can think about things. Language expressions can represent things, but also mind constructions or other language expressions. The object represented may be different, the phrase; "Yesterday I was thinking about holidays" may have as its object the thought with holidays as content and holidays as a real object that I mentioned yesterday. In both cases, the object of representation will be different in terms of the way of its existence.

What is presented by means of the content can exist as sensually presented, conceptually conceived, verbally spoken, sensory experienced, non-existent, etc. This way of existence of the content correlate is the way the object of representation exists. This is crucial as it reveals this property of representation that we can represent thoughts or images as well as states of affairs, and we distinguish between one type of representation and another. The basis of the distinction is not 
so much qualitative content but rather different type of internal information of the cognitive system concerning whether the content relates to a real object or to the thought construct. We can dream about red tomato, experience it or imagine it. The qualitative content can be the same in any of these cases. However, cognition provides us with additional knowledge about whether the object is dreamed, imagined or experienced in real life.

Apart from the content, its correlate, i.e. factor uniting its various components, and the way of existence of a correlate of content, the way of giving the content itself should also be distinguished. If a correlate of content is a real, existing thing, e.g. a horse, then a way of giving content might be a perception, an image, a conceptual or linguistic representation. Then, one would call it a perceived horse, an imaginary horse, conceptually represented or named horse. Although the external content correlate of a horse remains the same, one can spot different direct, internal object. However, in the case of the same content correlate, one can speak of a certain objective, though perhaps not representational (the same horse as an object of different representations) identity. It differentiates such situations as when one talks about a horse that one thinks of, imaginary horse or perceived horse, as well as a horse that one thinks of today, but saw yesterday. It also allows distinguishing between a horse that is being recalled and a horse only imagined. The way of giving content, as well as the way of the existence of content correlate, is not included in the content of the given representation itself, but rather given as additional, systematic knowledge. For example, one distinguished between a situation when one sees a yellow ball and a situation when one sees or hears the name "yellow ball" without any additional information contained in the expression "yellow ball" itself. One also distinguishes such situations when one sees a real horse, thinks of a real horse, imagines a real horse that description one reads, and when one recalls the horse one saw. In all these cases, the content correlate is real. However, the way in which content is given in the act of representation differentiates what corresponds to the internal object of representation and how the object of representation is 
given in the representation itself. Therefore, depending on the content and its presentation, one may finish with different internal object of representation created on basis of this correlate. In the first case, one have the object of observation, i.e. the real thing perceived sensually, in the second case, one have the notion of the real thing, in the third case the image of the real thing, and so on.

The object represented in a given act of representation is shaped in the context of additional complementary information, which is not included directly in the expression, but in the structure of meaning of the language itself or in the system of knowledge in general. In addition to the content revealed directly by the representation, additional knowledge is required to relate it to the content correlate, to recognize the identity of the content correlate in other acts of representation, or to assign additional content to the same correlate. This knowledge is obtained by other acts of representation and creates a system in which representing an object is possible. This allows one to assign different contents to the same correlate, which is one of the most vital cognitive processes. For example, the content of the expression "Morning Star", namely the content stating that this is a star visible in the morning sky is complemented by information that e.g. it is the same celestial body as the Evening Star or that this is the planet Venus.

This complementary content may, for example, relate to the complexity of representations, e.g. the fact that in the expression "a horse is herbivorous" there is a representation of representation, a general object, a schematic, abstract construct of the mind, which includes the content attributed to each real object defined as a horse and which is given in a concept or category of a horse, is represented ${ }^{14}$. It is the knowledge of the structure of the whole representation and its internal dependencies and its external references. The correlate of this content is the same as the content represented directly. This allows developing the knowledge about the cognitively represented subject.

In the above discussion, components describing the internal structure of the object have been distinguished, the differentiation

14 Cf. F. Dretske, Naturalizowanie umysłu, op. cit., 57. 
of which reflects different types of objects of representation. These are the aforementioned: (1) content represented directly; (2) the correlate of content; (3) the way of giving the content of representation; (4) the way of existence of the correlate of content; (5) the complementary content - systematic representation.

An object of representation, an object that is being represented, is given as the structure described above. However, the axis of this structure is the correlate of content, which can be called the represented object. But, as an object of representation, and not an element not included in the relation of representation, it must manifest the whole structure. Thus, the objects of representation (in the sense of their full structure) may differ in content, the way they are given and complementary knowledge, the correlate of content and its way of existence. The identity of an object of representation, despite the difference in content or the way it is given, determines the correlation between the content and the way it exists. The content assigned to an object determines exactly the aspect of the object reveals a given representation. A correlate of content can exist as, e.g. a real thing, an abstract, fictional object, etc.

Within such a defined structure of an object of representation, one can distinguish what can be called an intentional or internal object of representation. A relation of content with the way it is given and the correlate of content without specifying its way of existence is corresponding to the aforementioned notion. This object is, on the one hand, an internal object of representation defined by the content and the way it is given, and on the other hand, it transcends the correlate, it goes beyond the content itself and refers to the other elements of the structure. The relation between content, a way it is given and its correlate need to be complemented with the way of existence of the object that is represented, defining to which field of reality the correlate belongs to, e.g. real things, abstracts, fictitious, contradicting in terms of the content attributed to them, and so on. Taking into account the complex structure of the subject of representation makes it possible to remove the difficulties that arise in the case of non-existing referents. A fictitious object is an 
imaginary equivalent of logically possible or contradictory content and it exists as an element of thought, not as a real thing. Both the objects of thought and the real objects can be represented. They exist for representations in different ways, being the correlate of the content of representations. Pegasus does not exist as a horse with wings, it exists as a thought of "horse with wings". The thought with such content can be represented and in this sense, it is the object of representation, reflecting its entire structure together with how the content correlates and other components exist. In the case of a real thing, the correlate of content is that thing, however, cognitively expressed in terms of content and the way it is given, which determines the internal object of representation of that thing.

When we talk about the object of representation, we mean what the content directly refers to, what it indicates, what is its source and correlate, and what is given in representation in the form of the structure described. For example, in a sentence: "the neighbour's horse is old", a correlate of the name "neighbour's horse" is a specific external thing that exists in real life, while in a sentence: "the horse is a herbivorous animal" a correlate of the content of the name "horse" is not a single real horse, but an abstract general object, existing as a construct of thought, a correlate of the content of the concept of a horse, one schematic, cognitive approach to many real things. On the other hand, our image, e.g. of a flying horse, has a purely intentional content correlate and we can say that it exists e.g. in the field of fantasy creations conceived or described, similarly to a Pegasus, but it does not exist in reality, although similar to an diagonal square, it has an element uniting a given content. Only a representation for which a correlate of content exists, in reality, has a real thing as a denotation. It is then said that representation: a linguistic expression or a thought, has a real external object.

The way of presenting content differentiates the subject of the representation with the same content correlate. For example, a neighbour's horse, imagined, seen directly, seen in a reminder, described in words, may have the same content, the same correlate of content and the way it exists. However, there will be one subject of a presenta- 
tion, another one of imagination or description. However, they will all relate to the same thing represented in different ways.

The object of representation is a relational structure, constituted by consciousness, which can combine both mental and real elements and is based on information processes.

\section{CONCLUSIONS}

The article attempts to present the internal structure of the object of representation. For this purpose, some well-known analyses of the object and content of mental representations and of the distinction between the external object and the intentional object of thought and language have been cited. Individual components of the structure of the object of representation were distinguished and described against the background of these analyses. The presented structure makes it possible to reconstruct the diversity of what we call the object of representation and to show the structural dependence of the internal, intentional and external object of representation. An internal object is defined by its content, its way of presentation and its correlate. While an object external to thought and language (real) is defined by the full structure described in the article.

The thoughts that gave the basis for distinguishing the described structure of the object were as follows:

(1) The function of representation in relation to thought or language is much richer than the function of reality reflection, so it is necessary to take into account situations of representing only imaginary objects.

(2) There is given, associated with the representation, additional knowledge, not contained in the content of the representation itself, on how the correlate of content exists or about the source of the content represented, and this knowledge affects the constitution of the object of representation and should therefore be reflected in its structure.

(3) The object of representation is constituted in the relationship of cognitive or linguistic representation of reality or thought, and, therefore, there must be room in its structure for the relationship of external and internal elements to the individual process/act of representation itself. 
(4) The representation does not include its content, but always something else in opposition to it, even if different content is constituted in another act of representation, which justifies the adaptation of a distinction between the object and content of the representation in each situation.

It may be problematic to attribute the status of a general object to what is represented by the content of the concept. This is reflected by the fact that the use of the term is the use of representation. This is because the concept represents a category, a pattern that captures the characteristics of individually existing things, or a pattern that captures only the intended content. In both cases, it is a pattern conceived and general. There are no real-life general objects, but if a generalised model of individual things is represented, it is called a general object, as opposed to the content itself, which is the way it is represented, and not the individual real things that this model fulfils.

\section{BIBLIOGRAPHY}

Dretske F., Naturalizowanie umystu, transl. B. Świątczak, Warszawa 2004.

Frege G. , Sens i Znaczenie, in: Idem, Pisma semantyczne, transl. B. Wolniewicz, Warszawa 1977.

Krąpiec M. A., Język i świat realny, Lublin 1985.

Maciejczak M., Śriadomość i sens, Warszawa 2007.

Peirce S., Wybór pism semiotycznych, transl. R. Mirek, A. J. Nowak, Warszawa 1977. Russell B., Denotowanie, transl.J. Pelc, in: Logika i jezzyk: studia z semiotyki logicznej, ed. J. Pelc, Warszawa 1967. 